\title{
ECONOMIA E DIREITO NA TEORIA SISTÊMICA AUTOPOIÉTICA
}

\author{
Salete Oro Boff ${ }^{1}$ \\ Gabriel Zanatta Tocchetto ${ }^{2}$
}

RESUMO: Trabalho que desenvolve os conceitos do direito e da economia na Teoria Sistêmica Autopoiética com o objetivo de responder o que são de fato esses dois sistemas dentro da referida teoria. O texto desenvolve de forma que o primeiro capítulo trabalha com pressupostos teóricos ao entendimento teórico da construção autopoiética em Luhmann, ao tempo que o segundo capítulo desenvolve a ideia em específico dos dois sistemas em epígrafe. O trabalho conclui então pela descrição de ambos os sistemas a partir da comunicação operada neles mesmos, contando com os pressupostos comunicacionais desenvolvidos no texto.

Palavras-Chave: Direito. Economia. Teoria Sistêmica Autopoiética.

\section{ECONOMY AND LAW IN THE AUTOPOIETIC SYSTEMS THEORY}

\begin{abstract}
Paper which develops the concepts of law and economics in the Autopoietic Systems Theory with the objective of answering what are in fact these two systems within the said theory. The text develops itself in a way that the first chapter works with theoretical assumptions for the theoretical understanding of the autopoietic construction in Luhmann, while the second chapter develops the idea in specific of the two systems in evidence. The paper then concludes by describing both systems by the communication operated on themselves, relying on the communication presuppositions developed in the text.
\end{abstract}

Keywords: Law. Economy. Autopoietic Systems Theory.

\footnotetext{
${ }^{1}$ Pós-Doutora-UFSC. Doutora-UNISINOS. Professora do PPGDireito Mestrado Direito da IMED. Professora do Faculdade CNEC Santo Ângelo. Professora da UFFS - Universidade Federal da Fronteira Sul. Linha de Pesquisa "Efetividade do direito, da democracia e da sustentabilidade”. Grupo de Pesquisa CNPq "Direitos, Novas tecnologias e Desenvolvimento. Email: salete.oro.boff@gmail.com.

2 Mestrando em Direito pela Faculdade Meridional Imed. Bolsista FAPERGS-CNPq. Advogado. Bacharel em Direito pela Faculdade Meridional Imed. Pesquisador do projeto “A Proteção Jurídica da Inovação Aberta em Novas Tecnologias: Desafios de Gestão para os NITs”. E-mail: gztocchetto@gmail.com.
} 


\section{INTRODUÇÃO}

Apresentar uma estrutura pronta em relação ao que a Teoria Sistêmica Autopoiética propõe ao estudo da pós-modernidade ${ }^{3}$ não é um trabalho fácil, e, possivelmente, sequer um objetivo alcançável em sede de um único artigo. Apesar disso, a referida apresentação se mostra necessária em um contexto acadêmico onde as mais diferentes interpretações tanto da teoria, quanto da própria sociologia, ganham espaço, e o levantamento de pontos se mostra um problema teoricamente sensível ao desenvolvimento do trabalho.

O ponto de entrada ao contexto teórico, como colocado por Luhmann (2012, p.1/13), pode partir do elemento de que uma teoria sociológica não passa da tentativa de a sociedade descrever/entender a si mesma, sendo portanto em si uma representação de autorreferência desde o início. Para tanto, o autor descreve a sociologia em um contexto onde "What is described performs the description. In so doing it must therefore also describe itself. It must treat its subject as one that describes itself”4 (LUHMANN, 2012, p.1), sendo, portanto, a sociologia um elemento de autorreferência social.

O grande problema em relação à autorreferência sistêmica, no sentido de a sociologia representar uma tentativa de a sociedade observar a si mesma, pode ser observado a partir de um trecho presente no final da obra Transconstitucionalismo, que diz:

[...] todo observador tem um limite de visão no "ponto cego", aquele que o observador não pode ver em virtude da sua posição ou perspectiva de observação. Mas, se é verdade, considerando a diversidade de perspectivas de observação de alter e ego, que “eu vejo o que tu não vês”, cabe acrescentar que o "ponto cego" de um observador pode ser visto pelo outro. (NEVES, 2009, p. 297/298)

Em um contexto onde a sociedade, como sistema social de primeira ordem, não goza da possibilidade de feedback comunicativo por parte de observações de segundo grau ${ }^{5}$, ele carece da comunicação de observações externas que possibilitem tanto o diagnóstico de onde se encontra a cegueira, quanto o conhecimento da extensão que a auto-descrição praticada pela sociologia carrega.

\footnotetext{
${ }^{3}$ O presente artigo não busca a discussão do termo “pós-moderno” e sequer ousa qualificá-lo como termo correto. A expressão fora simplesmente utilizada por comodidade de entendimento, por remeter ao período pós $2^{\mathrm{a}}$ Guerra Mundial, podendo ser substituído em qualquer contexto por hiper-modernidade ou mesmo outro termo análogo.

4 Tradução livre: O que é descrito executa a descrição. O fazendo, a coisa deve portanto se descrever. A coisa deve tratar seu sujeito como algo que descreve a si mesmo.

${ }^{5}$ Uma vez que a sociedade é o único sistema de primeira ordem que opera comunicando.
} 
Talvez esse seja o motivo - a impossibilidade de auto-observação do Sistema Social pelo qual a sociologia se encontra em uma crise - seja ela real ou imaginária (IANNI, 1991, p. 195) - discutivelmente infindável. O grande problema pelo qual passa a sociologia - e, portanto, os sociólogos - pode ser diagnosticado como uma crise de paradigmas teórico-científicos (IANNI, 1991, p. 196), uma vez que a sociologia em si convive com o problema de estudar um objeto que continuamente se (re)produz, se complexifica e, ao fazê-lo, produz e constrói o próprio mecanismo que a estuda ${ }^{6}$. Resultado disso é uma produção científica na qual "Há uma espécie de sociologia da sociologia em toda a produção sociológica de maior envergadura.” (IANNI, 1991, p. 199), que mostra necessário ao referido ramo da ciência constantemente identificar o que estuda, uma vez que o evoluir da ciência modifica o próprio objeto estudado por ela, e não somente a observação praticada em relação ao objeto em questão ${ }^{7}$.

Para a estrutura teórica sistêmico-autopoiética, a referida crise da observação sociológica pode ser observada a partir do elemento da diferenciação sistêmica e a quantidade de possibilidades evolutivas, observacionais e comunicacionais que ela propicia aos subsistemas sociais - importante observar que a diferenciação sistêmica conta com o elemento comunicacional dos subsistemas do Sistema Social e pressupõe o fato de que não é um processo possível aos sistemas de primeira ordem ${ }^{8}$.

System differentiation is thus nothing other than recursive system formation, the application of system formation to its own result. The system in which further systems arise is reconstructed by a further distinction between subsystem and environment. From the perspective of the subsystem, the rest of the comprehensive system is now environment. For the subsystem the overall system now appears to be the unity of the difference between subsystem and subsystem environment. In other words, system differentiation generates intrasystemic environments. (LUHMANN, 2013, p. 3) ${ }^{9}$

O elemento de impossibilidade de diferenciação sistêmica significa para o Sistema Social, e, portanto, para a sociologia, diversos limites em relação a forma que é praticada a auto-

\footnotetext{
${ }^{6}$ Nesse sentido: "Our point of departure is that no society can reach itself through its own operations. Society has no address. Nor is it an organization with which one could communicate.” (LUHMANN, 2013, p. 167). Tradução livre: Nosso ponto de partida é o de que nenhuma sociedade pode alcançar a si mesma através de suas próprias operações. A sociedade não possui endereço. Nem mesmo é uma organização com a qual alguém possa se comunicar.

${ }^{7}$ Para um desenvolvimento da discussão sobre a cientificidade em si, vide SANTOS, 2008.

8 Aprofundamentos em relação ao elemento da diferenciação podem ser observados em LUHMANN 2013, especialmente nas páginas 1-26.

9 Tradução livre: Diferenciação sistêmica é portanto nada mais do que a formação recursiva de sistemas, a aplicação da formação sistêmica ao seu próprio resultado. O sistema no qual outros sistemas nascem é reconstruído por uma distinção mais profunda entre subsistema e ambiente. Da perspectiva do subsistema, o resto do sistema compreensível é agora ambiente. Para o subsistema o todo do sistema agora aparece como a unidade de diferença entre subsistema e ambiente subsistêmico. Em outras palavras, diferenciação gera ambientes intrasistêmicos.
} 
descrição pelo referido sistema de primeira ordem. Em um contexto onde não é possível que ocorram novas diferenciações sistêmicas, e no qual o Sistema Social é o único sistema que opera por meio do elemento da comunicação, o instituto da auto-descrição se mostra carente no que toca a observação de segundo grau que dá conta dos - acima mencionados - pontos cegos ${ }^{10}$.

Esse elemento de subjetividade no que toca o objeto de desenvolvimento científico, é um elemento que abrange todo o contexto das ciências sociais, uma vez que essas possuem como objeto de desenvolvimento científico a sociedade. A referida constatação possui caráter de importância em dois pontos para o presente trabalho: o primeiro sendo o de que será utilizado o paradigma sistêmico autopoiético para a prática da observação científica do trabalho, e o segundo para a observação de que ambos os sistemas - tanto o sistema jurídico quanto o econômico -, que serão "protagonistas" do desenvolvimento, possuem a carência objetiva descrita em relação ao objeto da sociologia como ciência.

Dessa forma, com o objetivo de responder ao problema do significado dos sistemas da economia e do direito para a Teoria Sistêmica Autopoiética, o presente trabalho se desenvolve em dois capítulos com os objetivos respectivos de: em primeiro lugar, trazer um aporte suficiente em termos de teoria para que se possibilite responder ao problema e; em seguida, apresentar uma conceituação dos sistemas da economia e do direito para a teoria em questão.

\section{A TEORIA SISTÊMICA AUTOPOIÉTICA}

O primeiro passo ao entendimento da teoria em questão se encontra na identificação do elemento dos sistemas, uma noção que “[...] tem estado de fato preocupada em descrever, representar, conhecer algo como unidade (enquanto tal) e não as partes que compõem tal unidade.” (RODRIGUES; NEVES, 2012, p. 21), exatamente pelo fato de que a noção de sistema busca a conceituação de diferença, motivo pelo qual se trata de uma teoria baseada no instituto da diferença.

Na observação da realidade por parte da Teoria Sistêmica Autopoiética, a descrição de sistemas a partir da lógica da diferença faz com que, antes mesmo de adentrar na sociologia e servindo ao propósito de observação mais detalhada do significado de sistemas como diferença -, o pesquisador se depare com a constatação de que a realidade - para além do que

10 A carência percebida no elemento dos pontos cegos é uma carência sanada pela observação da observação praticada pelos sistemas do entorno do sistema que observa (observação de segundo grau), o que não é possível ao Sistema Social. 
pode ser descrito como social ${ }^{11}$ - pode ser diferenciada na observação de três elementos sistêmicos objetivamente distintos, os elementos da sistêmica psíquica, a orgânica e a social (RODRIGUES; NEVES, 2012, p. 20). Desses três elementos iniciais ${ }^{12}$, ao estudo da Teoria Sistêmica Autopoiética no presente trabalho, necessário observar que a teoria se preocupa somente com os elementos que constituem a sistêmica social, leia-se: o Sistema Social.

If we describe society as a system, it follows from the general theory of autopoietic
systems that it must be an operationally closed one. At the level of system's own
operations there is no ingress to the environment, and environmental systems are just
as little able to take part in the autopoietic processes of an operationally closed
system. This is the case even, indeed especially, where such operations are
observations or operations whose autopoiesis requires self-observation - a difficult
thought that runs counter the entire epistemological tradition. (LUHMANN, 2012, p.
$49)^{13}$

Avançando para a observação do Sistema Social como objeto do desenvolvimento da sociologia, necessário tratar o fato de que “A comunicação corresponde à unidade elementar de todos os sistemas sociais.” (TONET, 2016, p. 130), ponto que torna possível determinar que o principal pilar do que pode ser chamado de sociedade no presente trabalho se limita ao contexto dos subsistemas que são capazes de operacionalizar o elemento da comunicação. Nesse sentido, importante a menção do fato de que a abertura do sistema social ao que compreende o elemento da comunicação, se dá porque a teoria pressupõe a comunicação como um fator socialmente construído, e portanto inerente e exclusivo do contexto do Sistema Social ${ }^{14}$.

A evidência da delimitação do que é de fato o objeto de pesquisa da sociologia aplicada ao presente trabalho, permite ao pesquisador a pergunta: como funcionam e se dividem esses sistemas marcados pelo elemento da diferença e operacionalizados pela característica da

\footnotetext{
${ }^{11}$ Importante a observação de que a Teoria Sistêmica Autopoiética se desenvolve a partir do paradigma teórico da Teoria Geral dos Sistemas, “[...] aprofundada por Ludwig von Bertalanffy, partindo da ideia de que a maior parte dos objetos da física, astronomia, biologia e sociologia foram sistemas.” (ROCHA; KING; SCHWARTZ, 2009, p. 14).

12 Sendo eles a representação dos três sistemas de primeira ordem: O Sistema da Psique, O Sistema Orgânico/Físico e o Sistema Social (BOFF; TOCCHETTO, 2017, p. 159-160).

13 Tradução livre: Se descrevermos a sociedade como um sistema, ela segue a partir da teoria geral dos sistemas que deve ser um sistema operacionalmente fechado. No nível das operações do próprio sistema não há ingresso para o ambiente, e sistemas ambientais [sistemas do ambiente] são tão pouco capazes de participarem nos processos autopoiéticos de um sistema operacionalmente fechado. Este é o caso mesmo, e de fato especialmente, onde tais operações são observações ou operações cujas autopoiese requer auto-observação - um pensamento difícil que vai de encontro com toda a tradição epistemológica.

14 Sobre a intensidade com a qual a comunicação se mostra paradigmática em relação ao desenvolvimento social, vide LUHMANN, 2012, p. 113-250.
} 
comunicação? Para responder a pergunta é necessário adentrar no funcionamento dos sistemas de segunda ordem, que são os sistemas desenvolvidos pela teoria como sistemas sociais.

\subsection{SOCIEDADE, AMBIENTE E SISTEMAS SOCIAIS (DE SEGUNDA ORDEM)}

Os sistemas sociais são sistemas caracterizados por serem operativamente fechados e cognitivamente abertos (autopoiéticos), dotados de significado, diferenciados de seus ambientes, capazes de praticar auto-descrições, de evoluir por meio das três fases da autopoiese - variação, seleção e reestabilização e de se acoplarem estruturalmente. A presente subdivisão do trabalho em tela busca apresentar e esclarecer esses termos para que seja possível trabalhar as hipóteses propostas a partir de uma base teórica.

\subsubsection{Abertura cognitiva e fechamento operativo}

A Teoria Sistêmica Autopoiética é uma teoria que se desenvolveu a partir da sistêmica trabalhada pelo sociólogo americano Talcott Parsons, quem Niklas Luhmann conheceu ao visitar Harvard durante seu ano sabático entre 1960 e 1961. A teoria desenvolvida pelo sociólogo americano se baseia na ideia de ação - e interação - social, a partir da ideia de que

The fundamental starting point is the concept of social systems of action. The interaction of individual actors, that is, takes place under such conditions that it is possible to treat such a process of interaction as a system in the scientific sense and subject it to the same order of theoretical analysis which has been successfully applied to other types of systems in other sciences.[...] The frame of reference concerns the "orientation" of one or more actors - in the fundamental individual case biological organisms - to a situation, which includes other actors. The scheme, that is, relative to the units of action and interaction, is a relational scheme. It analyzes the structure and processes of the systems built up by the relations of such units to their situations, including other units. It is not as such concerned with the internal structure of the units except so far as this directly bears on the relational system. (PARSONS, 2005, p. 1) ${ }^{15}$

\footnotetext{
15 Tradução livre: O ponto de partida fundamental é o conceito de sistemas sociais de ação. A interação de autores individuais, isso é, acontece em tais condições que é possível tratar tal processo de interação como um sistema no sentido científico e sujeitá-lo à mesma ordem de análise teórica a qual tem sido aplicada em outros tipos de sistemas em outras ciências. [...] O enquadramento da referência se importa com a”orientação” de um ou mais atores - no caso individual fundamental dos organismos biológicos - à uma situação, a qual inclui outros atores. O esquema, o é, relativo às unidade de ação e interação, é reacionário ao esquema. Ele analisa a estrutura e processos dos sistemas construídos pelas relações de tais unidades para suas situações, incluindo outras unidades. Não é não preocupado com a estrutura interna das unidades excepcionalmente até o ponto em que isso sustente diretamente o sistema relacional.
} 
Enquanto a sistêmica luhmanniana rechaça a ideia de ação social - para vir a trabalhar junto à ideia de Sistema Social, o fechamento operativo trazido pela autopoiese biológica - teoria desenvolvida pelos biólogos chilenos Humberto Maturana e Francisco Varela - a ideia de comunicação na sociedade.

A observação biológica desenvolvida por ambos os autores para observar a sociologia pode ser descrita da seguinte forma: Parsons trabalha a ideia dos sistemas sociais agindo como sistemas especializados no "organismo da sociedade”, em um contexto onde cada sistema biologicamente desenvolvido representa um sistema socialmente especializado em uma atividade essencial à vida do referido organismo no qual todos os sistemas agem e interagem de forma interdependente para que o organismo se mantenha funcional ${ }^{16}$; Por outro lado, Luhmann trabalha a teoria sistêmica autopoiética, uma teoria desenvolvida para a observação do funcionamento neurológico dos sistemas - que aqui são delimitados pelo limite entre o ser vivo e o ambiente -, em um contexto onde o sistema biologicamente autopoiético pratica uma operação que se atém aos limites do próprio sistema, ao tempo que adquire informações do ambiente a partir de um input que não permite ao ambiente operar diretamente dentro do sistema ${ }^{17}$.

Na lógica sistêmica autopoiética construída na sociologia, os limites sistêmicos dentro dos quais o fechamento operacional e a abertura cognitiva ocorrem, não podem ser observados de forma tão simples quanto na biologia, no entanto, é possível trazer certos elementos do desenvolvimento do sistema cognitivo biológico para o social (NEVES, 2013, p. 61). Essa situação se dá pelo fato de que um ser que possui capacidade de ser sensível ao ambiente no qual se encontra, nasce sem entender os limites físicos e operativos que o mesmo possui, e se essa diferenciação ocorre por meio da experiência sensível que esse sistema biológico passa. Com os sistemas sociais acontece de forma parecida, um contexto no qual o desenvolvimento de novos significados dentro de sistemas sociais pode gerar diferenciação sistêmica, e é por meio de comunicação e operação - elementos que exercem o papel das experiências sensíveis

\footnotetext{
${ }^{16}$ Em um contexto onde o sistema respiratório age de forma a trabalhar com a absorção de oxigênio por parte do organismo, e o circulatório age de forma a distribuir o oxigênio pelo corpo, a interação desses sistemas, dentro da lógica sistêmica de Parsons, se constrói de forma semelhante na sociedade.

17 Para desenvolver esse ponto da analogia feita pelo autor, pode-se visualizar a capacidade cognitiva de um sistema nervoso qualquer, que pratica as suas operações dentro dos limites que a existência do ser permite, ao tempo em que recebe informações a partir da sensitividade que seus limites sistêmicos têm em relação ao ambiente, e, trocar a limitação imposta pelo ambiente pela diferenciação de significado, que será desenvolvida no ponto 1.1.3 do presente trabalho.
} 
vividas pelo sistema biológico -, da abertura cognitiva, que um novo sistema passa a construir seu código de significado e a operar de forma adequada dentro de seus limites sistêmicos.

À Teoria Sistêmica Autopoiética, a colocação da abertura cognitiva e do fechamento operativo são conceitos extremamente caros, tanto do ponto de vista do desenvolvimento que elas propiciam, quanto - utilizando outro significado da palavra - pelo fato de esses serem elementos extremamente custosos à imagem da teoria no meio científico.

\begin{abstract}
A noção de fechamento operacional tem se constituído numa mudança paradigmática da chamada nova concepção sistêmica e, como todas as descontinuidades paradigmáticas, têm causado dificuldades/resistências para o seu entendimento. Por esse motivo, Luhmann a tem explicado de diversas maneiras [...], em muitos dos seus trabalhos, a partir da década de 80 , ao se referir ao sistema social. (RODRIGUES; NEVES, 2012, p. 25)
\end{abstract}

É verdade que à ideia de fechamento operativo e abertura cognitiva segue a lógica de que quanto mais operativamente fechado o sistema, mais cognitivamente aberto o mesmo será - o que leva ao desentendimento do fechamento (ROCHA; KING; SCHWARTZ, 2009, p. 6266), e à rejeição sumária (ROCHA; KING; SCHWARTZ, 2009, p.44-51) da teoria -, ao tempo que esses elementos permitem a prática de auto-referências, observações de segundo grau, a ocorrência de todas as fases da evolução sistêmica autopoiética, e o desenvolvimento da maioria dos elementos desenvolvidos pela teoria. No entanto, eventuais rechaços teóricos em relação ao referido desenvolvimento, necessitam ser, no mínimo, decisões informadas em relação à estrutura desenvolvida.

\title{
1.1.2 Significado
}

Significado é um elemento social essencial para o entendimento de tudo o que é operacionalizado e observado nos sistemas sociais, sendo um elemento que carrega consigo a possibilidade de diferenciação e se cumula com o passar do tempo e com a ocorrência da evolução sistêmica. Possivelmente o significado seja o elemento de maior simplicidade a ser desenvolvido no presente texto, no entanto, não é menos importante "For no societal operation can begin without using meaning” ${ }^{18}$ (LUHMANN, 2012, p. 18), sendo ele o elemento que funda o que chamamos de comunicação social.

\footnotetext{
18 Tradução livre: Porque nenhuma operação social pode começar sem fazer uso de significado.
} 
O significado é o pressuposto funcional que embasa a própria ideia de comunicação, sendo ele o que (1) dá sentido à qualquer forma utilizada para comunicar, (2) modifica objetivamente o que pode ser entendido a partir do que é comunicado, e (3) representa o resultado do que é construído a partir das comunicações operadas pelo sistema social.

Primeiramente, necessário observar o fato de que o significado é o pressuposto que dá sentido à ideia de comunicação. Para que seja possível observar a comunicação como um elemento fático, é necessário que seja possível também observar que os elementos comunicados tenham significado estruturado tanto para aquele que opera a comunicação quanto para aquele que a observa e a internaliza. Nesse contexto, importante observar o fato de que o significado da comunicação geralmente - se não sempre - se caracteriza por ser diferente a partir da observação do operador e do receptor.

Em segundo lugar, o significado é um elemento que se encontra necessariamente desvinculado do objeto da comunicação - a informação em si -, uma vez que o significado parte da interpretação dada pelo sistema à comunicação, sendo assim um elemento que varia a partir de qualquer elemento de mudança que possa ser evidenciado na comunicação, seja ele temporal $^{19}$, contextual ${ }^{20}$, ou de qualquer outra natureza relevante.

Por último, necessário observar o fato de que o significado é uma construção social constante, que trabalha tanto com a ideia de pressupostos comunicacionais quanto com a ideia de memória na sociedade (LUHMANN, 2012, p. 19). A evolução social - que ocorre com o passar do tempo - aumenta a quantidade de elementos possíveis de serem lembrados à carga de significantes para a comunicação social e complexifica os pressupostos comunicacionais pelos quais a comunicação social opera. Isso significa que a evolução social faz com que a comunicação social fique mais sofisticada e passe a pressupor uma carga crescente de elementos comunicacionais ao significado comunicativo.

\subsubsection{Diferenciação}

Apesar de discutível, é possível observar a diferenciação - para além de ser ponto nevrálgico ao desenvolvimento da Teoria Sistêmica Autopoiética - como elemento cujo

\footnotetext{
${ }^{19}$ Em um contexto, por exemplo, onde a evolução sistêmico-social faz com que comunicações como o casamento homosexual (para o direito brasileiro), e a utilização de maconha (para a moral de forma geral), por exemplo, sejam comunicações de informações que possuem cargas de significado extremamente diferentes se observadas a partir dos anos (também exemplificativos) de 1997 e de 2017.

20 No sentido de que, por exemplo, o elemento "prova” possui significados extremamente diferentes quando se observa um contexto educacional e um contexto jurídico.
} 
desenvolvimento se mostra mais intrinsecamente complexo dentro da estrutura teórica desenvolvida por Niklas Luhmann. Esse elemento pode ser evidenciado no fato de que na obra Die Gesellschaft der Gesellschaft (1998) ${ }^{21}$ são dedicadas, em momentos diferentes, cerca de 190 páginas ao tema.

A complexidade desse ponto se dá exatamente pelo fato de que a teoria em questão é estruturada sobre o conceito da diferença, uma vez que é por meio desse mecanismo que é desenvolvida a ideia de inclusão e exclusão (LUHMANN, 2013, p. 16-27), centro e periferia (LUHMANN, 2013, p. 42-50), autonomia e acoplamentos estruturais (LUHMANN, 2013, p. 108-114), irritações e valores (LUHMANN, 2013, p. 115-123) e outros elementos pontuais à teoria, tais como a diferenciação comunicacional entre significados, que possibilita ao teórico trabalhar a distinção entre sistema e ambiente.

De forma resumida, é possível afirmar que a diferenciação se mostra como elemento necessário ao mantimento da coesão do Sistema Social sob condições de crescimento, mesmo por ser um elemento que permite à sociedade admirar e criticar a si mesma (LUHMANN, 2013, p. 2). O elemento da diferenciação é o que permite a conceitos prontos ou não, construírem pontos de referência que os apresentem a necessária resposta sobre o que é ou não parte dos mesmos, ao tempo que não cobra do conceito um fechamento absoluto e nem mesmo uma completude de respostas.

\begin{abstract}
System differentiation is thus nothing other than recursive system formation, the application of system formation to its own result. The system in which further systems arise is reconstructed by a further distinction between subsystem and environment. From the perspective of the subsystem, the rest of the comprehensive system is now environment. For the subsystem the overall system now appears to be the unity of the difference between subsystem and subsystem environment. In other words, system differentiation generates intrasystemic environments. (LUHMANN, 2013, p. 3$)^{22}$
\end{abstract}

Luhmann identifica o elemento da diferenciação na sociedade como algo que constrói a “unidade da diferença” (2013, p.1), sendo esse, portanto, um elemento que não se faz elementar ao desenvolvimento estrutural da teoria em questão pelo fato de representar melhor o papel que os sistemas possuem em relação à elementos teóricos internos, mas pelo fato de considerar que

\footnotetext{
${ }^{21}$ Título que significa, literalmente, “A Sociedade da Sociadade”. Obra cuja tradução para o inglês foi utilizada no desenvolvimento da presente pesquisa, em LUHMANN 2012 e LUHMANN 2013.

22 Tradução livre: Diferenciação sistêmica é portanto nada mais do que a formação recursiva de sistemas, a aplicação da formação sistêmica ao seu próprio resultado. O sistema no qual outros sistemas nascem é reconstruído por uma distinção mais profunda entre subsistema e entorno. Da perspectiva do subsistema, o resto do sistema compreensível é agora ambiente. Para o subsistema o todo do sistema agora aparece como a unidade de diferença entre subsistema e ambiente subsistêmico. Em outras palavras, diferenciação gera ambientes intrasistêmicos.
} 
a diferença é um elemento basilar ao (surgimento e) desenvolvimento histórico-fático do que aqui tratamos como Sistema Social.

\subsubsection{Auto-Descrição}

A auto-descrição é um elemento sistêmico que trata de uma possibilidade criada pelo fechamento operativo do sistema e que trabalha o elemento da diferença como sua matéria de desenvolvimento (LUHMANN, 2013, 167). Trata-se do meio através do qual o sistema pode estruturar a sua diferença e descrever os limites sistêmicos da diferença sistema/ambiente por meio da qual se definem as observações e operações como tais.

Trata-se de um elemento sistêmico que tende a ficar cada vez mais sofisticado de acordo com o acontecimento sucessivo da evolução social, sendo um dos motivos que intensifica o fechamento operativo sistêmico ao tempo em que propicia uma maior abertura cognitiva. A prática da auto-descrição serve ao sistema como forma de complexificação de significado e de pressupostos comunicacionais, observação de estruturas internas, e possibilidade de identificação do que não pode ser operado pelo sistema, mas observado como ambiente.

Ao operar em vias de auto-descrição, imprescindível notar que o sistema não pode ser entendido nem como sujeito e nem como objeto (LUHMANN, 2013, 169) - nem mesmo como uma sobreposição de ambos -, mas como uma pressuposição dogmática (LUHMANN, 2013, 170) de existência para a cognição. Nesse contexto, um sistema social autopoiético pode ser observado como um elemento cognitivamente ativo que pressupõe a si mesmo, constrói a diferença em relação ao ambiente ${ }^{23}$ e é capaz de praticar auto-referência de forma a compreender a si mesmo.

This permits a new style of self-observation, namely, the attribution of topics to the system itself as opposed to its environment. The system reflects on its own unity as point of reference for observation, and as ordering perspective for ongoing reference. It is then advisable to produce texts that coordinate a multitude of such ways eventlike and situation-bound self-observations. (LUHMANN, 2013, 175) ${ }^{24}$

\footnotetext{
${ }^{23}$ Ao observar o ambiente, é possível que o sistema internalize elementos externos - por meio da abertura cognitiva - em um processo que pode ser traduzido como "referência do outro" (LUHMANN, 2013, 175), onde o outro deve ser observado como tudo o que não faz parte do sistema, leia-se: o ambiente.

24 Tradução livre: Isso permite um novo estilo de auto-observação, nomeadamente, a atribuição de tópicos ao próprio sistema como oposto ao seu ambiente. O sistema reflete sua própria unidade como ponto de referência para observação, e como perspectiva de ordenamento para referências em progresso. É então conveniente produzir textos que coordenam uma multitude de tais auto-observações de situações-limite e pseudo-eventos.
} 
A auto-descrição nos sistemas sociais conta com certos elementos nos quais o fechamento autorreferencial do sistema trabalha de forma a proporcionar um contexto salutar ao desenvolvimento da mesma - elementos como a reflexibilidade (NEVES, 2013, p. 64-65) e a reflexão (NEVES, 2013, p. 65-66) -, porém, necessário não olvidar o fato de que a observação de segundo grau ${ }^{25}$ serve como elemento basilar à solução da carência do Sistema Social que possui um ambiente que não é capaz de o descrever (NEVES, 2013, p. 66), contexto no qual o seu ponto cego não pode ser facilmente sanado.

\subsubsection{Evolução}

A evolução sistêmica é uma operação que ocorre - dentro da lógica dos sistemas operativamente fechados - dentro dos limites do sistema, esse é o elemento que dá nome à teoria, uma vez que o termo autopoiese designa a ideia de autoprodução ${ }^{26}$. O desenvolvimento da lógica que constrói o ponto é relativamente simples: sendo a evolução uma operação e os sistemas possuidores da característica de serem operativamente fechados, a operação de evolução é praticada dentro do próprio sistema, e, portanto, uma forma de autoprodução, a autopoiese.

Apesar de a evolução sistêmica ser caracterizada pela autoprodução operativamente fechada, necessário constatar que a abertura cognitiva sistêmica permite à autopoiese trabalhar em si elementos do ambiente do sistema que evolui, sem que o ambiente, em nenhum momento, opere de fato na autopoiese sistêmica. A evolução sistêmica em Luhmann, se desenvolve em três fases diferentes, sendo elas a variação, a seleção e a reestabilização (LUHMANN, 2012, p. 275-305).

A variação de elementos, é a fase da evolução por meio da qual são percebidos pontos de provocação, elementos de inovação, elementos que simplesmente não se encontram estabilizados dentro da estrutura sistêmica, ou simplesmente elementos que deixaram de ser irrelevantes ao contexto comunicacional do sistema e passam a ser observados como variação, sendo, portanto, necessariamente, a primeira fase da evolução sistêmica. Necessário observar

\footnotetext{
25 Caracterizada pela observação da descrição que o ambiente pratica em relação ao seu ambiente (ou seja, a descrição que um sistema faz de outro), servindo ao sistema que observa a si mesmo por meio da referida observação de segundo grau, entender como o se ambiente o percebe e desenvolver-se com mais esse elemento de cognição.

${ }^{26}$ Necessário observar o fato de que o termo autopoiese designa, de forma mais complexa do que a simples ideia de evolução, a ideia de autoprodução sistêmica, que compreende também o elemento do surgimento do sistema social autopoiético, uma conceituação paradoxal na qual o presente trabalho não pretende adentrar.
} 
que se trata da fase da evolução sistêmica por meio da qual é possível observar-se a maior parte de influência do ambiente em relação à operação de evolução, uma vez que a variação também serve ao sistema como forma de estabilizar novos elementos produzidos pelo ambiente.

Seleção é o nome dado à segunda fase da evolução sistêmica, na qual as variações passam por um processo de aceitação ou rechaço em relação à estrutura interna do sistema. É verdade que há a possibilidade de observar certa “seleção” em relação à observação de variação por parte de um sistema, no entanto, importante colocar que a seleção como parte da evolução sistêmica autopoiética, não se resume à observação ou não observação de elementos que podem ser ou não descritos como variação, mas na operação de selecionar como o sistema vai se modificar - ou deixar de se modificar - a partir do que já foi observado como variação ${ }^{27}$.

Já a reestabilização, como última fase da evolução sistêmica, possui um papel paradoxalmente importante. A reestabilização é a fase da evolução por meio da qual o sistema estrutura a resposta dada pela seleção em seu contexto operativo, o que significa que a seleção é absorvida pelo código comunicacional do sistema. O grande elemento de excentricidade da fase evolutiva em questão se encontra no fato de que a reestabilização sistêmica nunca pode aparecer como elemento de plenitude, uma vez que é necessário pressupor que o elemento reestabilizado ainda - e permanentemente - é passível de variação, ainda é passível de mudança ${ }^{28}$.

\section{A ECONOMIA E O DIREITO}

Observado o fato de que o problema desenvolvido pelo presente trabalho questiona a sobreposição da comunicação econômica em relação à comunicação jurídica no contexto social pós-moderno, o presente ponto busca apresentar ao leitor o que são esses sistemas, quais características eles carregam, e o que, de fato, significa falar sobre eles na Teoria Sistêmica Autopoiética.

Primeiramente, necessário ao desenvolvimento tomar como ponto de partida o fato de que à teoria em questão não permite ao teórico caminhar sob a égide de um desenvolvimento simples e objetivo, mas em um contexto desenvolvimentista demasiado complexo,

\footnotetext{
${ }^{27}$ Impreterível notar que a seleção pelo rechaço de uma variação não é a mesma coisa que uma situação onde a variação não seja levada em conta pelo sistema, uma vez que naquele caso, há uma reafirmação estrutural sistêmica no rechaço da variação.

${ }^{28}$ Esse elemento aparentemente paradoxal da reestabilização deriva da constatação de que o objetivo da evolução sistêmica não é a resolução do sistema como um problema, mas a sua perpetuação operativa.
} 
desprotegido das respostas simples e objetivas, bem como da compreensão integral do objeto estudado, a sociedade como sistema social.

\begin{abstract}
A desvantagem da teoria dos sistemas (se é que se pode tomá-la como desvantagem) está em sua elevada complexidade intrínseca e no correspondente caráter abstrato dos conceitos. Sua base de referência cognitiva é interdisciplinar e, com os meios habituais das disciplinas científicas (pode-se pensar aqui nas hiperdisciplinas, como física, biologia, psicologia, sociologia), é passível de ser apreendida apenas por segmentos. Não haveria jurista que pudesse estar suficientemente informado a esse respeito, sem falar na dificuldade de manter-se atualizado ante os rápidos desenvolvimentos. (LUHMANN, 2016, p. 31)
\end{abstract}

Logo, necessário ao desenvolvimento do presente ponto maturidade em relação ao fato de que o assunto dos sistemas econômico e jurídico, como assuntos de desenvolvimento teórico, não serão - e esse sequer é um objetivo tangível - esgotados, mas inicialmente desenvolvidos no presente texto.

\title{
2.1 O DIREITO COMO SISTEMA SOCIAL
}

Antes de adentrar no que de fato constitui o sistema social, cabe ao teórico apontar o fato de que "A teoria não pode distinguir entre lícito e ilícito (ainda que nem todo agir se ponha como problema legal em razão disso) [...] (LUHMANN, 2016, p. 35), o que significa que falar de sociologia jurídica não é o mesmo que falar de sistema jurídico. A sociologia jurídica se dirige à ciência, e não ao direito (LUHMANN, 2016, p. 41), e portanto não trabalha com a ideia de normatização, mas de descrição desse desenvolvimento a partir do código científico.

O direito - ou sistema jurídico - como sistema social autopoiético, é um elemento que possui diversas características peculiares, segurança e retidão em relação ao seu ambiente, e certa importância observacional em relação ao referido. Por ser o sistema responsável por decidir juridicamente, “compor formas (sentenças)” (LUHMANN, 2016, p. 46), se mostra necessário que o sistema jurídico evolua de forma cautelosa, procedimentalmente formal, e, principalmente, que ele evolua a partir da análise de elementos pretéritos em relação ao seu ambiente.

O elemento acima referido como segurança e retidão, em relação ao direito como sistema social, se dá pelo fato de que ao sistema em questão cabem as análises jurídicas sobre as observações praticadas por ele em relação ao seu ambiente e a si mesmo (NEVES, 2013, p. 81) - auto-observações -, em um contexto onde a produção da comunicação jurídica se caracteriza pelo desenvolvimento de respostas coerentemente construídas a partir do que a 
memória do sistema trata como dado, e, ao mesmo tempo, de acordo - até certo ponto - com as expectativas que o ambiente o coloca.

\begin{abstract}
Trata-se, contudo, de uma teoria reflexiva do sistema jurídico, impelida pela busca de contato interdisciplinar segundo a antiga tese fundamental. Segundo ela, normas não podem ser "deduzidas de fatos” e tampouco podem ser descritas como fatos se o objetivo for fazer jus a seu próprio valor, a seu pleno sentido e a seu caráter de reivindicação. [...] a partir do acontecido, a teoria do direito passa a se identificar como esforço de reflexão que pretende descobrir de que modo o direito se vê a partir de seu próprio entendimento. (LUHMANN, 2016, p. 16)
\end{abstract}

Esse contexto se dá pelo fato de que o direito trabalha programas finalísticos dentro de uma lógica de decisões programadas, o que significa tanto que o sistema jurídico trabalha sua estrutura a partir da lógica de programas condicionais e decisões programantes (CORREIA, 2014, p. 98), quanto que o direito analisa variações a partir das referidas decisões programantes - o que não indica, de qualquer forma, subordinação operativa do direito em relação ao sistema que opera os programas in casu.

O sistema que programa a estrutura por meio da qual o direito age, é o sistema político, que o faz por meio da construção legal, condicionando, mas não respondendo ao paradoxo da legalidade, do qual trata o sistema jurídico. Por esse elemento, necessário observar o fato de que o sistema político evolui e comunica a partir do código binário do poder/não poder, nunca chegando a comunicar o código legal/ilegal, trabalhado pelo sistema jurídico.

O direito como sistema opera por meio do paradoxo da legalidade e trabalha a comunicação binária lícito ilícito. Isso significa que o direito opera buscando a resposta para uma espécie de constante questionamento sobre a legalidade de elementos - quase que uma pergunta direta feita ao sistema por meio de variações na forma de "esse elemento de variação é legal?”. O paradoxo operado pelo sistema em questão se dá a partir do fato de que a estruturação de respostas sobre a legalidade/ilegalidade cria um contexto cada vez mais distinto de legalidade/ilegalidade, e, portanto, cada vez mais variações ${ }^{29}$ (NEVES, 2013, p. 83) - que é a lógica evolutiva de todos os sistemas autopoiéticos.

O fato de o sistema jurídico comunicar o código binário lícito/ilícito significa que, tanto na operação de seleção na evolução sistêmica, quanto em operações simples de comunicação a partir de provocações sistêmicas que não impliquem variações sistêmicas, espera-se do direito

\footnotetext{
${ }^{29}$ Quanto mais se conceitua a legalidade e a ilegalidade, mais elementos de legalidade e ilegalidade são possíveis de ser observados pelo sistema com novos elementos de distinção, e, portanto, mais elementos de variação relevantes ao sistema jurídico.
} 
uma resposta em relação à legalidade de elementos sociais, e, portanto, respostas em relação ao significado que a legislação deve ter na sociedade.

\subsection{ECONOMIA COMO SISTEMA SOCIAL}

O desenvolvimento do presente trabalho busca colocar uma imagem do sistema econômico na sociedade pós-moderna como vilão da corrupção sistêmica de seu ambiente entorno ou diferença - devido à sua centralidade e a forma como sua comunicação ocorre em detrimento das outras comunicações sociais em diversos momentos. No entanto, o presente ponto serve somente ao desenvolvimento do que a teoria sistêmica observa em relação à economia.

O sistema econômico talvez seja o sistema mais dinâmico e influente à sociedade pósmoderna. A economia, historicamente - e aqui sem a carga semântica inerente ao sistema econômico autopoiético -, é o sistema responsável pela quebra de barreiras comunicacionais e territoriais, desde o câmbio de mercadorias ao de informações, a economia opera como meio pelo qual o agente pode conseguir algo em qualquer lugar - discutivelmente, pode-se tratar da economia, histórica e socialmente falando, como elemento que pressupõe uma linguagem comum à sociedade.

Para além do contexto histórico, a economia - e agora com a carga semântica de sistema econômico autopoiético - possui a característica de lidar com o acesso de forma geral dentro da sociedade, seja como limitador ou como facilitador. Nesse sentido, é possível dizer que o problema da falta de recursos trabalha como forma de limitar os mais diversos sistemas sociais:

[...] ciência, esporte, religião. Todos estes âmbitos têm sua atuação limitada externamente pela escassez. O único sistema capaz de lidar com esse paradoxo é o econômico. Por isso, todos os outros sistemas pressupõem operações econômicas para poderem prosseguir. É o que Luhmann denomina interpenetração. Esses pontos precisam ser mais bem aclarados para que se compreenda toda a complexidade envolvida por qualquer operação social que lide com recursos escassos. ${ }^{30}$ (CORREIA, 2014, p. 68)

\footnotetext{
${ }^{30}$ Nesse sentido, importante colocar o fato de que a interpenetração sistêmica se dá no contexto de o paradoxo da escassez participar como caráter de limitação operativa sistemicamente constituída - faz parte da forma como o Sistema Social opera o fato de ser necessária a presença da comunicação do sistema econômico ao funcionamento de elementos que requerem recursos financeiros ao seu funcionamento -, o que se difere do elemento que será levantado no capítulo seguinte e será descrito como corrupção operativa econômica em relação ao direito.
} 
O sistema econômico, como referido, opera o paradoxo da escassez, que se dá pela atribuição artificial ${ }^{31}$ desse elemento aos mais diversos contextos comunicacionais “[...] tudo aquilo que pode ser comprado é comprável por meio de dinheiro” (CORREIA, 2014, p. 72). Diferentemente do direito - cuja simples variação comunicacional vincula o paradoxo operacional do sistema -, o paradoxo da escassez é gerado por uma operação social, a operação do acesso, que ao mesmo tempo gera o acesso - que resolve o problema da escassez -, e exclui do acesso aqueles - elementos, sistemas, programas, situações - que não são operam o acesso, gerando escassez (CORREIA, 2014, p. 69), ao tempo que o elemento de troca - não de escambo, mas de compra financeira na qual se troca a escassez do recurso financeiro pela escassez do bem pelo qual o recurso financeiro está sendo trocado - gera esse contexto de acesso/escassez de forma oposta.

A economia em si trabalha com o código ter/não ter, por meio do qual opera tanto a produção da escassez, quanto o paradoxo em si, e é exatamente no código binário de comunicação da economia como sistema autopoiético que se desenvolve o problema introduzido ao presente trabalho. Pode não ser possível identificar o paradoxo da escassez em comunicações corrompidas pela economia - pontualmente pelo fato de serem comunicações em si -, no entanto, é possível diagnosticar a comunicação econômica em operações jurídicas e dos mais diversos sistemas sociais, ambiente da economia.

\section{CONCLUSÃO}

O presente trabalho objetivou desenvolver e responder à pergunta: “o que significam para a Teoria Sistêmica Autopoiética os sistemas da economia e do direito?” e, após certo desenvolvimento teórico em termos na teoria, é possível simplificar a resposta para essa pergunta até o ponto em que se diz: os sistemas jurídico e econômico nada mais são para a teoria do que a comunicação jurídica e a comunicação econômica respectivamente. Por óbvio, o entendimento dessa resposta ao problema pressupõe amplo conhecimento teórico acerca da teoria em si, o que é exatamente o principal objetivo científico da construção feita no presente trabalho.

\footnotetext{
31 A artificialidade do paradoxo da escassez se dá pelo fato de que "Não há bens que sejam, per se, escassos" (CORREIA, 2014, p. 68), e a escassez se mostra como um elemento desenvolvido no interior do Sistema Social relacionado ao problema do acesso (CORREIA, 2014, p. 68-69) como operação geradora.
} 
A própria evolução como conceito da Teoria Sistêmica Autopoiética autopoiética trata de simplificar a comunicação ampliando os pressupostos comunicacionais, o que é exatamente o esforço feito no presente texto. O desenvolvimento de uma teoria complexa de forma que se possa chegar a uma conclusão comunicativamente simples e enxuta, é exatamente o que a autopoiese opera nos sistemas sociais, sendo ela, portanto, geradora de infindos processos de complexificação (e aumento) de pressupostos comunicacionais ao tempo de exercer a simplificação da comunicação em si.

\section{REFERÊNCIAS}

BOFF, Salete Oro ; TOCCHETTO, Gabriel Zanatta. Sistema de Patentes na Saúde: O Sistema Econômico Sobrepondo-se à Comunicação da Saúde. In: Salete Oro Boff; Vinícius Borges Fortes; André Frandoloso Menegazzo; Gabriel Zanatta Tocchetto (Org.). Propriedade Intelectual e Gestão da Inovação. Erechim: Deviant, 2017, v. 1, p. 157-170.

CORREIA, José Gladiston Viana. Sociologia dos Direitos Sociais: escassez, justiça e legitimidade. São Paulo: Saraiva. 2014.

IANNI, Octavio. A Crise de Paradigmas na Sociologia. Revista Crítica de Ciências Sociais, Campinas, v. I, n. 32, p. 195-215, jun. 1991.

LUHMANN, Niklas. Theory of Society volume 1. Tradução de Rhodes Barrett. Stanford: Stanford University Press. 2012. Press. 2013.

Theory of Society volume 2. Tradução de Rhodes Barrett. Stanford: Stanford University . O Direito da Sociedade. 2016. São Paulo: Martins Fontes. 2016.

NEVES, Marcelo. Transconstitucionalismo. São Paulo: Martins Fontes. 2009.

Entre Têmis e Leviatã: Uma relação difícil. 3. ed. São Paulo: Martins Fontes. 2013.

PARSONS, Talcott. The Social System. Londres: Routledge, Taylor and Francis Group. 2005.

ROCHA, Leonel Severo; KING, Michael; SCHWARTZ, Germano. A Verdade Sobre a Autopoiese no Direito. Porto Alegre: Livraria do Advogado. 2009. 
RODRIGUES, Leo Peixoto; NEVES, Fabrício Monteiro. Niklas Luhmann: A sociedade como sistema. Porto Alegre: Edipucrs. 2012.

SANTOS, Boaventura de Souza. Um Discurso Sobre as Ciências. 5. ed. São Paulo: Cortez Editora. 2008.

TONET, Fernando. Reconfigurações do Constitucionalismo: evolução e modelos constitucionais sistêmicos na pós-modernidade. 2. ed. Rio de Janeiro:Lumen Juris. 2016. 